\title{
Speed of lexical and nonlexical processing in French: The case of the regularity effect
}

\author{
JOHANNES C. ZIEGLER \\ CNRS and Université de Provence, Marseille, France \\ CONRAD PERRY \\ University of Hong Kong, Hong Kong, and \\ Macquarie University, Sydney, Australia \\ and \\ MAX COLTHEART \\ Macquarie University, Sydney, Australia
}

\begin{abstract}
Words with irregular spelling-sound correspondences are read aloud more slowly than words with regular spelling-sound correspondences. This so-called regularity effect is modulated by word frequency, with low-frequency words showing larger costs than do high-frequency words. Because French has more regular spelling-to-sound correspondences than English, we expected a different pattern in French than in English. This was indeed the case, since regularity effects were obtained for both highand low-frequency words in French. We further showed that a French implementation of the dual-route cascaded model could not account for this pattern. In additional simulations, we investigated whether this failure was due to lexical processes being too fast (leaving little time for the nonlexical route to interfere) or nonlexical processes being too slow. The results showed that only speeding up the nonlexical route allowed the model to capture the data. This suggests that the delayed phonology assumption that characterizes nonlexical processing in the original model needs to be abandoned in a more regular orthography.
\end{abstract}

In the area of word recognition and reading, remarkable progress has been made, thanks to the development of computational models (e.g., Coltheart, Rastle, Perry, Langdon, \& Ziegler, 2001; Plaut, McClelland, Seidenberg, \& Patterson, 1996; Seidenberg \& McClelland, 1989; Zorzi, Houghton, \& Butterworth, 1998). These models are evaluated with regard to theoretically meaningful marker effects that allow us to gain insights into the basic mechanisms underlying skilled reading.

The regularity effect, or more precisely, the interaction between the effects of spelling-to-sound regularity and word frequency, is one critical marker of reading performance (Andrews, 1982; Baron \& Strawson, 1976; Paap \& Noel, 1991; Seidenberg, Waters, Barnes, \& Tanenhaus, 1984; Taraban \& McClelland, 1987). This interaction reflects the finding that reading aloud of low-frequency words, but not of high-frequency words, is slower and more error prone for words with irregular spelling-to-

This research was supported by an Australian Research Council Key Centre Grant. We thank Mathilde Muneaux for collecting the data and Alain Content, Ken Forster, and an anonymous reviewer for insightful comments. Correspondence concerning this article should be addressed to J. C. Ziegler, Laboratoire de Psychologie Cognitive, CNRS and Université de Provence, Case 66, 3 place Victor Hugo, 13331 Marseille Cedex 3, France (e-mail: ziegler@up.univ-mrs.fr). sound correspondences than for words with regular correspondences (but see Jared, 1997, 2002).

An irregular correspondence is defined as one that violates the grapheme-to-phoneme conversion (GPC) rules of a language. For example, comb is irregular because the second-position grapheme $(o)$ has an exceptional pronunciation. The dual-route cascaded model (DRC; Coltheart et al., 2001) accounts for the regularity effect by suggesting that there are two routes to pronunciation: a lexical and a nonlexical route. The lexical route operates in parallel on the letter string: Letter units activate word units in the orthographic lexicon, which activate phonological units in a phonologicallexicon, and those activate phoneme units in a phonological output system (i.e., the phoneme output buffer). The nonlexical route applies GPC rules in a serial manner from left to right. That is, for each grapheme, the appropriate GPC rule is applied, and the corresponding phoneme unit in the phoneme output buffer receives some activation (which adds to the activation it receives from the lexical route). Irregular words, such as comb, suffer a latency cost because there is competition in the phoneme output buffer. In the case of $c o m b$, the lexical route activates the phoneme $/ \mathrm{o} /$, whereas the nonlexical route activates the phoneme $/ \mathrm{o} /$. Because each phoneme unit within each set of phonemes (i.e., each phoneme in each output position) causes lateral 
inhibition across all phonemes, the rise of activation of the correct phoneme /o/ is slowed by inhibition caused from activation generated from the regularization phoneme $/ \mathrm{s} /$.

A delicate issue for dual-route models is that of finding an appropriate balance between the two routes. If the parameters are set so that the lexical route is too fast, no regularity effect will be observed, not even for low-frequency words. If the parameters are set so that the nonlexical route is too fast, irregular words will be regularized, rather than being correctly pronounced, but with a latency cost. For English, previous simulation work has shown that one parameter set can be found that will allow the model to simulate the critical frequency $\times$ regularity interaction, together with a number of other theoretically important benchmark effects (e.g., Coltheart \& Rastle, 1994; Rastle \& Coltheart, 1998, 1999a, 1999b).

One factor that is likely to affect the balance between lexical and nonlexical processing is the nature of a language's writing system. In such languages as SerboCroatian, Italian, French, and German, letters or letter groups map relatively consistently onto sounds. In these languages, readers can and do rely to a large extent on nonlexical spelling-to-sound conversion (Frost, Katz, \& Bentin, 1987; Goswami, Ziegler, Dalton, \& Schneider, 2001). In English, however, the relation between letters and sounds is often equivocal. This means that to overcome spelling-to-sound irregularity, readers might require stronger lexical processing and/or weaker nonlexical processing. Thus, if the balance between lexical and nonlexical processing is language specific (Frost et al., 1987; Katz \& Feldman, 1983; Katz \& Frost, 1992; Paulesu et al., 2000), this would have important consequences for understanding and modeling reading in different languages.

In the present research, we investigated the relative strength of lexical and nonlexical processing in French, using the regularity effect as a critical marker. French is more regular than English with regard to the spelling-tosound mapping. Gak (1976) estimated that $95 \%$ of French words could be assembled correctly on the basis of spelling-to-sound rules (for similar estimates, see Peereman \& Content, 1999; Ziegler, Jacobs, \& Stone, 1996). We were interested in two questions. First, is there a regularity effect in French, and does it interact with frequency? Second, would a French implementation of the DRC model capture these effects, using the same pa- rameter set as the one that produced satisfying results in English?

\section{EXPERIMENT 1}

In the present experiment, we investigated the size of the regularity effect in high- and low-frequency French words. If French readers rely to a greater extent on nonlexical processing, one might expect relatively larger regularity effects in French than in English. More important, if the balance between lexical and nonlexical processing is shifted so that both routes operate at similar speeds (unlike for English, where the nonlexical route is slower than the lexical route), one might obtain a regularity effect for both high- and low-frequency words. Indeed, Content (1991) found such a pattern. Because his study relied to a great extent on multisyllabic words, and given that most computational models have not yet been extended to multisyllabic words, it was of interest to replicate his effect with monosyllabic words only. A delayed-naming task was added in order to estimate what portion of the regularity effect results from articulatory or postperceptual differences between the items (e.g., Balota \& Chumbley, 1985).

\section{Method}

Participants. Seventy-two undergraduate psychology students from the Université de Provence participated in the immediatenaming task. Fifteen additional participants performed the delayednaming task. All were native French speakers.

Stimuli and Design. The design resulted from a factorial manipulation of word frequency (high vs. low) and regularity (regular vs. irregular). Sixty monosyllabic words were selected from the LEXOP database (Peereman \& Content, 1999). Thirty words were of low frequency (fewer than 25 occurrences per million), and 30 words were of high frequency (more than 25 occurrences per million). Within each frequency group, half of the items $(n=15)$ were regular, whereas the other half were irregular. Irregular words were defined as violating French GPC rules. Regular and irregular words were matched pairwise on initial onset, word frequency, number of orthographic neighbors $(N)$, and letter length. Item characteristics are given in Table 1 . Note that high-frequency words had significantly more neighbors than did low-frequency words. If anything, this should amplify potential frequency effects. There were no significant differences on any of the other item variables (for statistical tests, see Table 1). All the items are listed in the Appendix. Item means can be found at http://www.maccs.mq.edu.au/ max/DRC/.

Procedure. In the immediate-naming task, a fixation point was presented for $500 \mathrm{msec}$, followed by the word, which was displayed

Table 1

Item Characteristics in Experiment 1

\begin{tabular}{|c|c|c|c|c|c|c|c|}
\hline \multirow[b]{2}{*}{ Item Variables } & \multicolumn{2}{|c|}{ High Frequency } & \multicolumn{2}{|c|}{ Low Frequency } & \multicolumn{3}{|c|}{ Statistical Tests } \\
\hline & Irregular & Regular & Irregular & Regular & Freq & Reg & Freq $\times$ Reg \\
\hline Frequency (per million) & 195.1 & 185.6 & 7.8 & 7.0 & $p<.0001$ & n.s. & n.s. \\
\hline Orthographic neighbors & 3.9 & 3.6 & 1.8 & 2.1 & $p<.05$ & n.s. & n.s. \\
\hline Word length & 4.1 & 4.2 & 4.2 & 4.3 & n.s. & n.s. & n.s. \\
\hline Position of irregularity & 2.8 & $\mathrm{n} / \mathrm{a}$ & 3.3 & $\mathrm{n} / \mathrm{a}$ & n.s. & $\mathrm{n} / \mathrm{a}$ & $\mathrm{n} / \mathrm{a}$ \\
\hline Delayed naming (msec) & 335 & 327 & 360 & 353 & $p<.005$ & n.s. & n.s. \\
\hline
\end{tabular}

Note-Freq, frequency; Reg, regularity; Freq $\times$ Reg, frequency $\times$ regularity interaction. 
in lowercase letters for $500 \mathrm{msec}$ in the center of the screen. The participants were asked to name the word as quickly as possible. In the delayed-naming task, the word was presented for 1,000 msec. After a blank interval of $1,400 \mathrm{msec}$, a response cue was presented. The participants were asked to withhold responding (while holding the word "on the tip of the tongue") until the response cue appeared. Stimulus presentation and data recording were performed using PsyScope (Version 1.1; Cohen, MacWhinney, Flatt, \& Provost, 1993). Responses were recorded with a digital tape recorder for offline scoring. The participants received 10 practice trials.

\section{Results}

Immediate naming. Latency and error data for highand low-frequency regular and irregular words are presented in Figure 1A. Response latencies that were below $250 \mathrm{msec}$ (anticipations) or above 2,500 msec (voice key failures) were excluded from the analyses. This procedure affected 71 responses ( $1.61 \%$ of the data). One item from the high-frequency group (together with its matched regular control) had to be excluded because it was incorrectly classified as irregular. The data were submitted to an analysis of variance (ANOVA) with frequency and regularity as factors.

The data exhibited strong regularity effects for both high- and low-frequency words (39 and $45 \mathrm{msec}$, respectively). In comparison, the frequency effect was rather small $(10 \mathrm{msec})$. There was no interaction between the effects of frequency and regularity. This pattern was confirmed in the ANOVA. For response times, the main effect of regularity was significant by subjects and items $\left[F_{1}(1,71)=50.6, p<.0001 ; F_{2}(1,54)=11.6\right.$, $p<.001]$. The frequency effect was not significant $\left[F_{1}(1,71)=2.8, p<.10 ; F_{2}(1,54)=1.1\right]$. The interaction between the effects of frequency and regularity was not significant (both $F_{\mathrm{s}}<1$ ).

With regard to errors, the data exhibited a significant effect of regularity ${ }^{1}\left[F_{1}(1,71)=124.5, p<.0001\right.$;

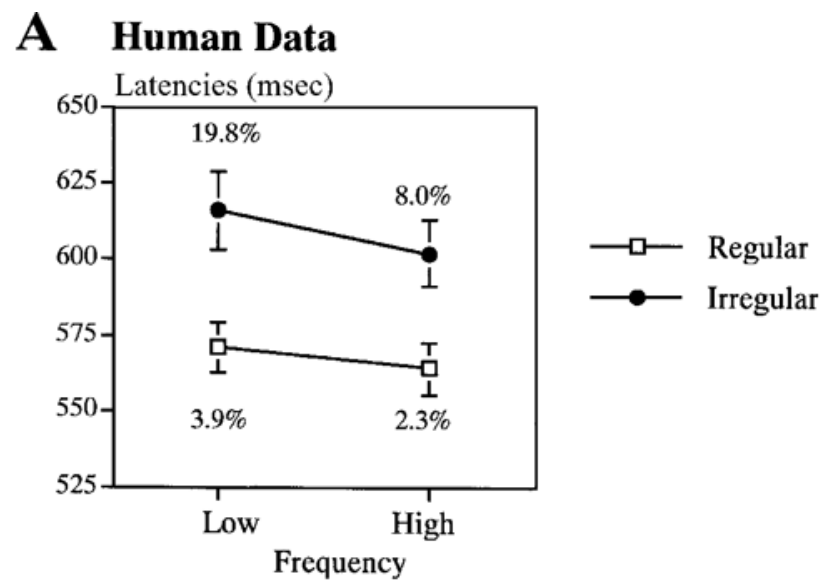

\section{B DRC orginal parameter set C DRC fast nonlexical}
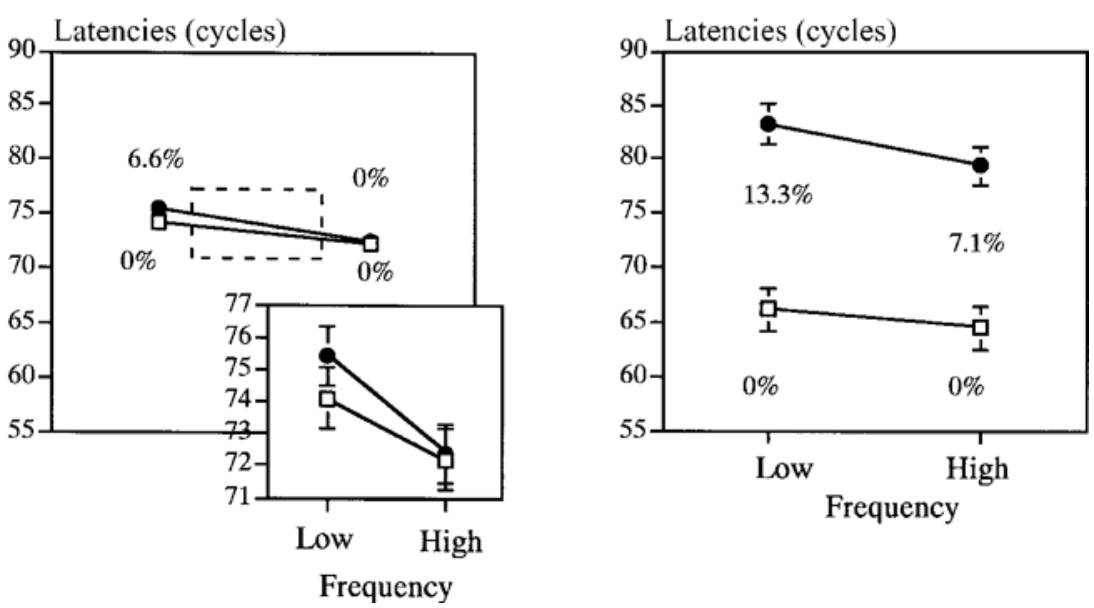

Figure 1. Reading aloud performance of the participants on regular and irregular highand low-frequency words (A), as compared with simulation data for the same items using a French version of the original dual-route cascaded (DRC) model (B) and a version of the model in which the nonlexical route was speeded up $(C)$. 
$\left.F_{2}(1,54)=10.3, p<.002\right]$ and frequency $\left[F_{1}(1,71)=\right.$ $\left.75.2, p<.0001 ; F_{2}(1,54)=4.0, p<.05\right]$. The participants made fewer errors on regular than on irregular words $(3.0 \%$ vs. $14.0 \%)$ and on frequent than on infrequent words ( $5.2 \%$ vs. $12.0 \%)$. The interaction between the effects of frequency and regularity was significant by subjects, but not by items $\left[F_{1}(1,71)=75.3, p<.0001\right.$; $\left.F_{2}(1,54)=2.3, p<.15\right]$. About $75 \%$ of the errors on irregular items were regularization errors. As is predicted by dual-route models, their proportion was similar for high- and low-frequency items $(80.2 \%$ vs. $73.6 \%$, respectively). This difference was not statistically significant $(p>.70)$.

Delayed naming. Mean latencies are presented in Table 1 . Neither the regularity effect nor the interaction with frequency was significant (all $F_{\mathrm{S}}<1.7, p>.20$ ), suggesting that regularity effects in the immediate-naming task are unlikely to result from articulatory differences between the items. Also, an analysis of covariance on the immediate-naming latencies, factoring out differences in delayed naming, confirms the existence of a significant regularity effect $[F(1,53)=10.1, p<.01]$ and no interaction between frequency and regularity $(F<1)$. Only the frequency effect carried over to the delayed-naming $\operatorname{task}\left[F_{1}(1,71)=10.8, p<.01 ; F_{2}(1,54)=9.2, p<.01\right]$. Although it is quite common to find reliable frequency effects in delayed naming, it is unclear why the frequency effect in our delayed-naming task was numerically larger than that in the immediate-naming task. However, keep in mind that different participants were used in both tasks and that the sample size was much smaller in the delayed-naming task.

\section{SIMULATION 1}

The goal of Simulation 1 was to explore whether an implementation of the DRC model for French would be able to simulate the regularity effect for both high- and low-frequency words (details of the French model can be found at http://www.maccs.mq.edu.au/ max/DRC). The same words as those in Experiment 1 were submitted to the French DRC model operating with the original parameter set developed for English.

The simulation results are presented in Figure 1B. These data were submitted to a two-way ANOVA with frequency and regularity as factors. The model exhibited no regularity effect $(F<1)$. There was a small frequency $X$ regularity interaction, but it failed to reach significance $(F<1)$. Only the word frequency effect was significant $[F(1,53)=6.7, p<.05]$. With regard to errors, the model showed no significant main effects or interactions (all $F_{\mathrm{s}}<1$ ).

Altogether, the model operating with the original parameter set failed to capture the two main empirical patterns. First, the model produced a significant frequency effect, but the frequency effect was not significant in the human data. Second, the model exhibited no regularity effect for either high- or low-frequency words, again un- like the human data. There are two possible explanations for the failure of the French DRC (using the original parameter set) to capture the data pattern. First, it could be that the lexical route is faster in French than in English, due to differences in the size of the respective lexicons ( 2,443 vs. 7,446 for French and English, respectively). A lexical route that is faster in the French than in the English model would cause the regularity effect in the French simulations to be absent. This is because a faster lexical route would mean that there would be less time for the nonlexcial route to interfere with processing and, hence, cause a regularity effect.

The second possibility is that the nonlexical route of the French DRC is too slow to produce the large regularity effect obtained in the human data. In the original DRC model, the nonlexical route is artificially slowed down (it starts only 10 cycles after the lexical route). This was done because a fast nonlexical route in the English model produced too many regularization errors, especially on words that have an irregular grapheme in an early letter position (Rastle \& Coltheart, 1999b). In French, the situation is quite different, because there is much less irregularity in the grapheme-phoneme mapping. Therefore, the greater overall regularity of French might allow for a nonlexical route that runs faster than that of the English model.

The advantage of an implemented model is that these different possibilities can be tested in simulations. In Simulation 2, we investigated whether there are differences in the speed of the lexical route between English and French. In Simulation 3, we investigated whether the French DRC could produce a regularity effect when the lexical route of the French model has the same speed as that of the English model. Finally, in Simulation 4, we explored whether speeding up the nonlexical route would allow the model to simulate the human data.

\section{SIMULATION 2}

The purpose of Simulation 2 was to check whether the lexical route in the French model is faster than the lexical route in the English model. Such a difference might explain why the French model does not produce a significant regularity effect when operating with the English parameter set, because, if lexical processing is faster in French than in English, the nonlexical route has little opportunity to affect lexical processing. To check whether there are speed differences in lexical processing between the two languages, we ran all words from the English $(N=7,446)$ and French $(N=2,443)$ lexicons through the respective DRC models while switching off the nonlexical route. This way, we obtained a pure estimate for the speed of lexical processing in French versus English.

The results showed that the English model with only the lexical route turned on required an average of 78.4 cycles $(S D=3.9)$ to name all English words. In comparison, the French model with only the lexical route turned 
on required an average of 77.1 cycles $(S D=6.4)$. Thus, lexical processing in French was about 1.3 cycles faster than lexical processing in English, despite the use of the same parameter set. Although this difference was quite small, it was nevertheless highly significant $[F(1,9987)=$ $132.1, p<.0001]$. Thus, it is logically possible that the faster lexical processing of the French model prevents potential regularity effects from occurring. Whether this is the case for our stimulus set was tested in Simulation 3.

\section{SIMULATION 3}

In this simulation, the speed of the lexical route of the French model was slowed down to match that of the English lexical route. This was done by reducing the parameter that governs letter-to-word activation from 0.062 to 0.058 . To check whether this modification would indeed result in identical lexical-processing speeds for both languages, we repeated Simulation 2. The results showed that the French model with reduced letter-toword activation now required the same number of cycles as the English model $(78.5$ cycles vs. 78.4 cycles for French and English, respectively) when reading aloud all the words from the lexicon. There was no statistically significant difference between the models $[F(1,9887)=$ $0.32, p>.50]$.

After we had produced a French DRC model, in which the lexical-processing speed matched that of the English model, the question was whether this modified French model would produce the same regularity effect as that observed in the human data or, at least, a regularity $\times$ frequency interaction like that typically observed in English experiments. Thus, the items of Experiment 1 were again run through the French DRC model with a somewhat slower lexical route.

The results were almost identical to those presented in Figure 1B (Simulation 1) - that is, no regularity effect for high-frequency words (73.4 vs. 73.6 for irregular vs. regular items, respectively), a small regularity effect for low-frequency words (77.1 vs. 75.6 for irregular and regular items, respectively), and a relatively large frequency effect (73.5 vs. 76.3 for high- and low-frequency items, respectively). The two-way ANOVA confirmed that the frequency effect was significant $[F(1,53)=8.5, p<$ $.005]$. However, neither the regularity effect nor the regularity $\times$ frequency interaction reached significance (all $F$ s $<1$ ). Thus, even if the French lexical route runs at the same speed as the English lexical route, the French DRC produces neither a regularity effect nor a regularity $\times$ frequency interaction. These results rule out the possibility that the slightly faster processing speed of the French lexical route in the original model (Simulation 1) is responsible for the model's failure to capture the human data.

Nevertheless, it is puzzling that the French DRC did not produce the typical frequency $\times$ regularity interaction even when the lexical-processing speed matched that of the English model. That is, if the normally slow nonlexical route is sufficiently fast to affect lexical processing in the original English simulations, it should also affect lexical processing in the French simulations, because rule application in the model is not affected by the number of alternative pronunciations of a grapheme. Therefore, if a slow nonlexical route is fast enough to produce a frequency $\times$ regularity interaction in English, it should also do so in French. Yet the French DRC does not quite show this pattern, although the effects do go in the right direction (no regularity effect for high-frequency words and a small regularity effect for low-frequency words). Given that differences in lexical-processing speed cannot explain the absence of the regularity $\times$ frequency interaction, as was shown in Simulation 3, it must be the case that irregular French items differ from irregular English items on an important dimension. One dimension that is crucially important to the DRC is the position of irregularity. Because of the serial nature of the nonlexical route, the earlier the irregularity occurs in a word, the more it will interfere with lexical processing. In fact, Rastle and Coltheart (1999b) have shown that the regularity effect was strongest for first-position irregular items, weaker for second-position irregular items, and almost absent for third-position irregular items. As is shown in Table 1, the average position of irregularity for the French items is quite late (third phoneme). Thus, this could explain why the French DRC produces only a weak regularity $X$ frequency interaction-namely, because most French items are third position irregular and the speed of the nonlexical route in the original model was set so that third position irregular items do not produce regularity effects.

\section{SIMULATION 4}

Having shown that differences in lexical-processing speed were not responsible for the model's failure to capture the human data, we turned up the nonlexical processing speed, in order to see whether this change would produce both regularity effects for high- and low-frequency words and a reduced frequency effect. The two parameters that govern the speed of the nonlexical route were changed in the following way: The GPC onset parameter was changed from 10 to 0 cycles, which meant that the nonlexical route now started at exactly the same time as the lexical route, and the GPC speed parameter was changed from 17 to 10 cycles, which meant that the interval between the assembly of each letter was reduced from 17 to 10 cycles. Apart from these two changes, no other changes were made.

The simulation results are presented in Figure 1C. Visual inspection of the figure shows a striking fit between the simulation results and the human data. The French DRC model with the faster nonlexical route now produced a regularity effect for both high- and low-frequency words and a fairly small overall frequency effect. This pattern was assessed in an ANOVA. The analysis showed a significant effect of regularity $[F(1,51)=64.5, p<.0001]$ 
and no interaction between the effects of regularity and frequency $(F<1)$. As in the human item data, the frequency effect was small and failed to reach significance $[F(1,51)=$ $1.96, p<.20]$.

The model produced fewer errors than did the participants. In particular, it made no errors on regular words at all. However, if one takes the effect sizes into account (i.e., irregular minus regular words), the size of the regularity effect for high- and low-frequency words is strikingly similar to that shown in the human data $(13.3 \%$ simulated errors vs. $15.9 \%$ observed errors and $7.1 \%$ simulated errors vs. $5.7 \%$ observed errors for low- and high-frequency words, respectively). As in the human data, the apparent interaction between regularity and frequency failed to reach significance (both $F_{\mathrm{S}}<1$ ). Only the main effect of regularity reached significance $[F(1,54)=3.1, p<.05]$.

\section{GENERAL DISCUSSION}

The interaction between the effects of regularity and frequency has been a powerful marker effect for examining the balance between lexical and nonlexical processing in the reading of English (e.g., Paap \& Noel, 1991; Seidenberg et al., 1984; but see Jared, 1997, 2002). The existence of these effects in skilled reading and acquired dyslexia was a major force in driving the development of dual-route models and in defining their major processing assumptions (e.g., the relative speed of lexical vs. nonlexical processing routes).

Surprisingly, very few studies on regularity effects were conducted in more regular languages, which may be partially due to the fact that there are only very few genuine irregular words in these languages (e.g., Ziegler, Perry, \& Coltheart, 2000). In this study, we investigated the regularity effect in French. French has more regular spelling-to-sound correspondences than does English but still contains a small number of irregular words that are neither loan words nor international words. The results showed that reading aloud was slower for irregular than for regular words, and this was the case for both high- and low-frequency words. A similar pattern was previously reported by Content (1991). Together, these two studies suggest that the frequency $\times$ regularity interaction, which has often been considered universal across languages, is not found in the more regular French language. Instead, the present data suggest that there are fundamental differences in terms of lexical and nonlexical processing speeds between languages. Most important, the more regular spelling-to-sound mapping seems to allow French readers to rely more heavily on nonlexical spelling-to-sound conversion. The price to pay for the stronger reliance on nonlexical processes are quite large regularity effects for both high- and low-frequency words.

The simulation studies provide further evidence for these conclusions. A French version of the original DRC model, in which the nonlexical route is slower than the lexical route, does a poor job of simulating the human data. It does not capture the regularity effect, and it over- estimates the size of the frequency effect. Because what matters for simulating the effects is the relative speed of the two routes, there are two possibilities that would explain the model's failure to capture the human data: Either the lexical route of the French model is too fast (leaving little time for the nonlexical route to interfere), or the nonlexical route is too slow. The simulations showed that although speed differences in lexical processing between the French and English models exist (Simulation 2), they cannot explain the model's failure to capture the human data (Simulation 3 ). Instead, speeding up the nonlexical route allowed the French DRC to perfectly simulate the human data (Simulation 4). The idea of speeding up is actually slightly misleading, because it is the nonlexical route of the original English model that was voluntarily slowed down (delayed phonology assumption) to handle the high degree of irregularity in English. All that was really necessary in the French simulations was to drop the delayed phonology assumption by allowing the nonlexical route to start at the same time as the lexical route. Thus, the simulations directly support the claim that readers of more regular orthographies can and do rely to a greater extent on nonlexical processes for reading aloud (Frost et al., 1987; Goswami et al., 2001; Paulesu et al., 2000; Ziegler, Perry, Jacobs, \& Braun, 2001).

Finally, it should be pointed out that the model's ability to simulate the human data by allowing the nonlexical route to run faster than that of the English model does not mean that this is the only correct approach for simulating the data. Our goal was somewhat more modest, in the sense that we wanted to investigate which processing assumptions of a well-understood and fully specified computational model have to be changed when the model is transferred to a more regular language. Certainly, there might be other approaches to simulating the data, and we look forward to seeing how they might come to simulate the present data (e.g., Ans, Carbonnel, \& Valdois,1998; Plaut et al., 1996; Zorzi et al., 1998).

In summary, the present study provides both empirical and computational data in support of the idea that the contributions of lexical and nonlexical processing in reading aloud can differ across orthographies. As in our previous modeling work for German (Ziegler et al., 2000), we showed that the dual-route architecture was appropriate for simulating the effects. However, assumptions about processing speed within these dualroute models should not be taken for granted. Rather, they seem to be somewhat language specific. In particular, differences in the consistency of spelling-to-sound relations seem to be responsible for differences in lexical and nonlexical processing speeds across orthographies.

\section{REFERENCES}

ANDREws, S. (1982). Phonological recoding: Is the regularity effect consistent? Memory \& Cognition, 10, 565-575.

Ans, B., CARBonnel, S., \& VAldoIs, S. (1998).A connectionist multipletrace memory model for polysyllabic word reading. Psychological Review, 105, 678-723. 
Balota, D. A., \& Chumbley, J. I. (1985). The locus of word frequency effects in the pronunciation task: Lexical access and/or production? Journal of Memory \& Language, 24, 89-106.

BARON, J., \& STRAWSON, C. (1976). Use of orthographic and wordspecific knowledge in reading words aloud. Journal of Experimental Psychology: Human Perception \& Performance, 2, 383-393.

Cohen J. D., MacWhinney B., Flatt, M., \& Provost, J. (1993). PsyScope: An interactive system for graphic designing and controlling experiments in the psychology laboratory using Macintosh computers. Behavioral Research Methods, Instruments, \& Computers, 25, 257-271.

Coltheart, M., \& Rastle, K. (1994). Serial processing in reading aloud: Evidence for dual-route models of reading. Journal of Experimental Psychology: Human Perception \& Performance, 20, $1197-$ 1211.

Coltheart, M., Rastle, K., Perry, C., Langdon, R., \& Ziegler, J. C. (2001). DRC: A dual route cascaded model of visual word recognition and reading aloud. Psychological Review, 108, 204-256.

CONTENT, A. (1991). The effect of spelling-to-sound regularity on naming in French. Psychological Research, 53, 3-12.

Frost, R., Katz, L., \& BEnTIN, S. (1987). Strategies for visual word recognition and orthographic depth: A multilingual comparison. Journal of Experimental Psychology: Human Perception \& Performance, 13, 104-115.

GAK, V. G. (1976). L'orthographe du français. Paris: SELAF.

Goswami, U., Ziegler, J. C., Dalton, L., \& Schneider, W. (2001). Pseudohomophone effects and phonological recoding procedures in reading development in English and German. Journal of Memory \& Language, 45, 648-664.

JARED, D. (1997). Spelling-sound consistency affects the naming of high-frequency words. Journal of Memory \& Language, 36, 505-529.

JARED, D. (2002). Spelling-sound consistency and regularity effects in word naming. Journal of Memory \& Language, 46, 723-750.

KATZ, L., \& Feldman, L. B. (1983). Relation between pronunciation and recognition of printed words in deep and shallow orthographies. Journal of Experimental Psychology: Learning, Memory, \& Cognition, 9, 157-166.

KATZ, L., \& FROST, R. (1992). The reading process is different for different orthographies: The orthographic depth hypothesis. In R. Frost \& L. Katz (Eds.), Orthography, phonology, morphology, and meaning (pp. 45-66). Amsterdam: Elsevier.

PAAP, K. R., \& Noel, R. W. (1991). Dual-route models of print to sound: Still a good horse race. Psychological Research, 53, 13-24.

Paulesu, E., McCrory, E., Fazio, F., Menoncello,L., Brunswick, N., Cappa, S. F., Cotelli, M., Cossu, G., Corte, F., Lorusso, M., PeSenti, S., Gallagher, A., Perani, D., Price, C., Frith, C. D., \& Frith, U. (2000). A cultural effect on brain function. Nature Neuroscience, 3, 91-96.

Peereman, R., \& Content, A. (1999). LEXOP: A lexical database providing orthography-phonology statistics for French monosyllabic words. Behavior Research Methods, Instruments, \& Computers, 31, 376-379.

Plaut, D. C., McClelland, J. L., Seidenberg, M. S., \& Patterson, K. (1996). Understanding normal and impaired word reading: Computational principles in quasi-regular domains. Psychological Review, 103, 56-115.

RAstle, K., \& Coltheart, M. (1998). Whammies and double whammies: The effect of length on nonword reading. Psychonomic Bulletin \& Review, 5, 277-282.
RASTle, K., \& ColtheArt, M. (1999a). Lexical and nonlexical phonological priming in reading aloud. Journal of Experimental Psychology: Human Perception \& Performance, 25, 461-481.

Rastle, K., \& Coltheart, M. (1999b). Serial and strategic effects in reading aloud. Journal of Experimental Psychology: Human Perception \& Performance, 25, 482-503.

SeidenberG, M. S., \& MCClelland, J. L. (1989). A distributed developmental model of word recognition and naming. Psychological Review, 96, 523-568.

Seidenberg, M. S., Waters, G. S., Barnes, M. A., \& Tanenhaus, M. K. (1984). When does irregular spelling or pronunciation influence word recognition? Journal of Verbal Learning \& Verbal Behavior, 23, 383-404.

TARABAN, R., \& MCClElland, J. L. (1987). Conspiracy effects in word pronunciation. Journal of Memory \& Language, 26, 608-631.

ZIEGLER, J. C., JACOBS, A. M., \& Stone, G. O. (1996). Statistical analysis of the bidirectional inconsistency of spelling and sound in French. Behavior Research Methods, Instruments, \& Computers, 28, 504515.

Ziegler, J. C., Perry, C., \& Coltheart, M. (2000). The DRC model of visual word recognition and reading aloud: An extension to German. European Journal of Cognitive Psychology, 12, 413-430.

Ziegler, J. C., Perry, C., Jacobs, A. M., \& Braun, M. (2001). Identical words are read differently in different languages. Psychological Science, 12, 379-384.

Zorzi, M., Houghton, G., \& Butterworth, B. (1998). Two routes or one in reading aloud? A connectionist dual-process model. Journal of Experimental Psychology: Human Perception \& Performance, 24, 1131-1161.

\section{NOTE}

1. Regularity effects for error rates were obtained despite the fact that, for two irregular items ( $c r o c$ and broc), the regularized pronunciations were accepted as correct responses, because in some French dialects the final $c$ in these words is indeed pronounced.

\section{APPENDIX \\ Items Used in the Experiment and the Simulations}

High-frequencyirregular. clef, dix, femme, fier, fils, gars, huit, gaie, sens, mars, net, nerf, ville, chœur

High-frequencyregular: clos, dur, force, fine, fond, gras, hors, gré, soir, marche, née, noce, vivre, claire

Low-frequencyirregular. broc, cerf, clerc, cul, croc, fjord, jonc, raid, porc, scout, so $^{\circ} 1$, tronc, tram, hall, rhum

Low-frequency regular: brut, seau, clore, crin, cap, fiole, jade, rapt, pneu, scalp, saut, trêve, trot, hausse, rein

(Manuscript received October 23, 2001; revision accepted for publication September 3, 2002.) 